\title{
Effect of tranquilization and anesthesia on high-resolution electrocardiographic indices of dogs in the chronic chagasic myocardiopathy
}

[Efeito da tranquilização e da anestesia nos índices da eletrocardiografia de alta resolução em cães com miocardiopatia chagásica crônica]

\author{
W.L. Ferreira ${ }^{1}$, D.P. Paula ${ }^{2}$, N. Nunes ${ }^{3}$, A.A. Camacho ${ }^{3}$ \\ ${ }^{1}$ Curso de Veterinária - FOA - UNESP \\ Rua Clóvis Pestana, 793 \\ 16050-680 - Araçatuba, SP \\ ${ }^{2}$ Aluno de pós-graduação - FCAV-UNESP - Jaboticabal, SP \\ ${ }^{3}$ Faculdade de Ciências Agrárias e Veterinárias - UNESP - Jaboticabal, SP
}

\begin{abstract}
RESUMO
Avaliou-se o efeito da tranquilização e da anestesia sobre os índices da eletrocardiografia de alta resolução (ECGAR) em cães portadores de doença-de-chagas na fase crônica indeterminada. Foram utilizados oito cães, adultos, sem raça definida, fêmeas, submetidas a seis protocolos (grupos). No grupo 1 , os animais estavam sem efeito de tranquilização ou anestesia; no grupo 2, foram tranquilizados com acepromazina; no 3, foram tranquilizados com a associação acepromazina e buprenorfina; no 4, estavam sob anestesia geral inalatória com isofluorano; no 5, sob anestesia geral inalatória com sevofluorano; e no 6 , sob anestesia com propofol. Os animais foram submetidos a todos os protocolos, com um período de 15 dias entre cada avaliação. Não se verificou alteração significativa na duração do complexo QRS e do LAS40 entre os grupos, e o RMS40 permaneceu sem alteração significativa. O nível de ruído foi significativamente menor nos grupos 4, 5 e 6 em relação ao grupo 1 . A anestesia facilitou o registro da ECGAR sem alterar os índices eletrocardiográficos .
\end{abstract}

Palavras-chave: cão, doença-de-chagas, eletrocardiografia de alta resolução, anestesia

\begin{abstract}
The effect of tranquilization and anesthesia on high-resolution electrocardiography (HRECG) indices of dogs in the undetermined chronic phase of Chagas' disease was studied. Eight adult female mongrel dogs were submitted to six protocols: group 1: animals not submitted to tranquilization or anesthesia; group 2: tranquilization with acepromazine; group 3: tranquilization with a combination of acepromazine and buprenorphine; group 4: general inhalatory anesthesia with isoflurane; group 5: general inhalatory anesthesia with sevoflurane; group 6: anesthesia with propofol. The animals were submitted to all protocols at an interval of 15 days between assessments. HRECG was performed in the time domain. Regarding the electrocardiographic parameters analyzed, no significant difference in the duration of the QRS complex or LAS40 was observed between groups. Similarly, the RMS40 remained unaltered. The noise level was significantly lower in the groups anesthetized with isoflurane, sevoflurane and propofol compared to the group not submitted to tranquilization or anesthesia. Anesthesia facilitated the HRECG recording without altering the electrocardiographic indices obtained.
\end{abstract}

Keywords: dog, Chagas' disease, high-resolution electrocardiography, anesthesia

Recebido em 2 de junho de 2005

Aceito em 16 de outubro de 2006

E-mail: wluis@fmva.unesp.br 


\section{INTRODUCTION}

Cardiac arrhythmias are heart rhythm disorders commonly diagnosed in patients with cardiovascular diseases (Jacobs, 1996). Their possible emergency nature requires the precise identification of patients prone to the development of these events. In this respect, high-resolution electrocardiography (HRECG) is a computerized noninvasive method used to identify patients who are at a high risk of presenting sustained ventricular tachycardia based on the detection of so-called late potentials (Hatém et al., 1993). The process consists of calculating the average of various heart beats, their filtration and subsequent amplification in order to detect electrical potentials of low amplitude and high frequency that occur at the end of the QRS complex or beginning of the ST segment and are related to the presence of fragmented and delayed electrical activity in the ventricles (Moffa, 2000), characterizing a noninvasive marker of a reentry arrhythmogenic substrate commonly implied in the genesis of severe ventricular arrhythmias associated with a risk of sudden death. With respect to the use of animal models for the study of cardiac arrhythmias, Janse et al. (1998) reported that the data provided by animal investigations have undoubtedly contributed to the planning of diagnostic and therapeutic strategies for the control of arrhythmias. At present, the study of experimental myocardiopathies in animals, such as that caused by Chagas' disease is considered to be an important model for the characterization of the regulatory and physiopathological mechanisms of cardiac function (Klein and Camacho, 1997).

Muscle tremors impair HRECG recordings by causing undesired noise. An adequate reduction in the noise level is essential for HRECG analysis. In this respect, the use of tranquilizing or anesthetic drugs may facilitate the restraint of the animals, leading to lower muscle activity. However, little is known about the effects of these drugs on HRECG indices.

Therefore, the objectives of the present study were to determine HRECG indices in dogs with chronic chagasic myocardiopathy in an attempt to identify the potential risks of ventricular tachycardia and sudden death and to determine the effect of tranquilizing and anesthetic drugs on the electrocardiographic indices obtained.

\section{MATERIAL AND METHODS}

Eight adult female mongrel dogs in the undetermined chronic phase of chagasic myocardiopathy, with a mean body weight of $10.71 \pm 3.13 \mathrm{~kg}$, were used. The animals received a commercial balanced ration and water ad libitum.

The dogs were inoculated intraperitoneally in 1994 with 1000 Trypanosoma cruzi (Colombian strain) trypomastigotes per $\mathrm{kg}$ body weight, an ideal dose for the induction of the undetermined chronic phase, and then kept in an isolation kennel. The number of trypomastigotes in the inoculum was determined in $5 \mu 1$ sodium citratecontaining blood obtained by intracardiac puncture from albino mice infected with $T$. cruzi. The blood was mounted between a slide and coverslip and trypomastigotes were counted under a light microscope equipped with a 40 objective and 10 eyepiece (400X) in 100 fields. For quantification of the number of parasites in milliliters, the result was multiplied by the correction factor of the microscope. Based on this number, dilutions were prepared in $0.9 \%$ saline, followed by re-counting until obtaining the dose per kg weight.

The sera of all animals obtained before inoculation and during the undetermined chronic phase were submitted to indirect immunofluorescence at dilutions ranging from 1:20 to 1:5120. Each negative control serum was diluted 1:40. The antigen substrate was prepared with epimastigote forms of $T$. cruzi strain Y obtained from cultures provided by the Departamento de Parasitologia, Microbiologia e Imunologia da Faculdade de Medicina de Ribeirão Preto da Universidade de São Paulo.

All animals were submitted to the same anesthetic protocol at a minimum interval of 15 days between each assessment, for a total of six treatments. Treatment 1: control animals (not submitted to tranquilization or anesthesia); treatment 2: tranquilization with acepromazine ${ }^{1}$; treatment 3 : tranquilization with a combination of acepromazine and buprenorphine ${ }^{2}$; treatment 4: general inhalatory anesthesia with isoflurane ${ }^{3}$; treatment 5: general

\footnotetext{
${ }^{1}$ Acepran $0.2 \%$ - Laboratório UNIVET, São Paulo, SP.

${ }^{2}$ Temgesic - Laboratório Schering-Plough, São Paulo, SP.

${ }^{3}$ Forane - Laboratório Cristália, Itapira, SP.
} 
inhalatory anesthesia with sevoflurane ${ }^{4}$ and treatment 6: general anesthesia by continuous infusion of propofol ${ }^{5}$.

HRECG recordings were obtained with a digital Holter analysis kit using HRECG software ${ }^{6}$. The animals were maintained in left lateral decubitus and the following three orthogonal derivations (X, $\mathrm{Y}$ and $\mathrm{Z}$ ) were recorded: $\mathrm{X}$ : between the right (negative electrode) and left (positive electrode) 5th and 6 th intercostal space at the junction between the upper and middle third of the chest; Y: positioned in the region of the manubrium (negative electrode) and xiphoid cartilage (positive electrode); $\mathrm{Z}$ : on the $\mathrm{T} 7$ spinous process (negative electrode) and in the opposite ventral aspect (positive electrode).

The animals were kept in a silent, dimly illuminated room and a trichotomy was performed for placement of the electrodes using adhesive gel electrodes ${ }^{7}$. A strip of adhesive tape was placed over the electrode to allow greater adhesion to the skin.

The electrocardiographic signals were obtained and processed in the following sequence: 1) recording of the three orthogonal derivations ( $\mathrm{X}, \mathrm{Y}$ and $\mathrm{Z}$ ) which permitted measurement of the cardiac potentials in the sagittal, transverse and horizontal plane; 2) recording of an average of 1500 cardiac cycles, with rejection of aberrant complexes or those containing many artifacts; 3) 100 times amplification of each derivation for voltage and four times for the time scale; 4) processing of the $\mathrm{X}, \mathrm{Y}$ and $\mathrm{Z}$ derivations in bidirectional filters, and 5) combination of the filtered derivations into a magnitude vector (root square of the sum of $x^{2}+y^{2}$ $+z^{2}$ ). This combination is a measure of the duration of high frequency activity of all three derivations.

This processing permitted the acquisition of the following parameters: duration (ms) of the filtered QRS complex, duration (ms) of the low amplitude signal (below $40 \mu \mathrm{V}$ ) for the last $40 \mathrm{~ms}$ of the QRS complex (LAS40), and the root mean square voltage for the last $40 \mathrm{~ms}$ of the QRS complex (RMS40)

In treatment 1 , the animals were kept free of any tranquilization or anesthesia effect in a silent, dimly illuminated room. After $30 \mathrm{~min}$ of adaptation, the HRECG recording was started. In treatment 2,

\footnotetext{
${ }^{4}$ Sevorane - Abbott Laboratórios do Brasil, São Paulo, SP.

${ }^{5}$ Diprivan - Zeneca Farmacêutica do Brasil, São Paulo, SP

${ }^{6}$ Model CSK 540D - Cardio Sistemas Com. Ind. Ltda., São Paulo, SP.

${ }^{7}$ Foam ECG electrodes with gel - EMBRAMAC, Itapira, SP.
}

acepromazine was administered intravenously at the dose of $0.1 \mathrm{mg} / \mathrm{kg}$ body weight, and HRECG recording was started $10 \mathrm{~min}$ after application. In treatment 3, acepromazine was applied intravenously at the dose of $0.1 \mathrm{mg} / \mathrm{kg}$ body weight, intravenously, immediately followed by intravenous administration of $0.01 \mathrm{mg} / \mathrm{kg}$ buprenorphine. HRECG recording was started 10 min after the administration of buprenorphine. In treatments 4 and 5, general anesthesia was induced by the intravenous administration of propofol at the dose necessary to permit orotracheal intubation $(8.0 \pm 2.0 \mathrm{mg} / \mathrm{kg})$. The animals were then intubated with a Magill catheter whose diameter was compatible with the size of the animal, and immediately submitted to inhalatory anesthesia with isoflurane (group 4) or sevoflurane (group 5). In both groups, the drug diluted in pure oxygen was administered through a semi-closed anesthetic circuit $^{8}$ at 1.4 the minimum alveolar concentration measured with a digital gas analyzer ${ }^{9}$ at a flow rate of $30 \mathrm{ml} / \mathrm{kg} / \mathrm{min}$. HRECG was started $30 \mathrm{~min}$ after administration of the volatile agent. In treatment 6 , general anesthesia was induced by the administration of $10 \mathrm{mg} / \mathrm{kg}$ propofol, followed by continuous infusion of this drug through an infusion pump $^{10}$ at $0.5 \mathrm{mg} / \mathrm{kg} / \mathrm{min}$. HRECG recording was started after the beginning of continuous infusion of propofol.

Analysis of variance was performed and group means were compared by Tukey test (Zar, 1996).

\section{RESULTS}

The individual HRECG are shown in Table 1. According to characteristics described in the literature (Calvert, 1998), animal 1 presented a filtered QRS duration above normal (>75ms) and a reduced RMS40 $(<117 \mu \mathrm{V})$ (Fig. 1). These two electrocardiographic alterations characterize the occurrence of a late potential.

Regarding the protocols evaluated, no significant difference in the duration of the filtered QRS complex, LAS40 or RMS40 was observed between treatments, indicating that tranquilization or anesthesia did not significantly alter HRECG parameters (Table 2). Analysis of each treatment separately showed no significant difference in the analyzed electrocardiographic characteristics.

\footnotetext{
${ }^{8}$ TAKAOKA - model Nissei - KT 10

${ }^{9}$ DIXTAL - model 2010 LCD

${ }^{10}$ SAMTRONIC - model 670T
} 
It should be emphasized that the drugs used did not have any effect on HRECG parameters in the animal showing a late potential, and no ventricular arrhythmias were observed in all dogs.

The noise level was significantly higher in animals not submitted to tranquilization or anesthesia compared to those anesthetized with isoflurane, sevoflurane or propofol (Table 2). With respect to tranquilization with acepromazine or acepromazine plus buprenorphine, no significant difference in the noise level was observed compared to the control group. Propofol induced a significant increase in heart rate compared to the other treatments.

Table 1. High resolution electrocardiography (HRECG) values obtained for the eight dogs with chronic chagasic myocardiopathy not submitted to sedation or anesthesia

\begin{tabular}{ccccc}
\hline Dog & $\begin{array}{c}\text { QRS } \\
(\mathrm{ms})\end{array}$ & $\begin{array}{c}\text { LAS40 } \\
(\mathrm{ms})\end{array}$ & $\begin{array}{c}\text { RMS40 } \\
(\mu \mathrm{V})\end{array}$ & $\begin{array}{c}\text { Noise } \\
(\mu \mathrm{V})\end{array}$ \\
\hline 1 & 84 & 16 & 74 & 0,5 \\
2 & 58 & 10 & 158 & 0,6 \\
3 & 76 & 19 & 174 & 0,5 \\
4 & 68 & 16 & 379 & 0,4 \\
5 & 75 & 16 & 119 & 0,4 \\
6 & 61 & 14 & 380 & 0,5 \\
7 & 74 & 24 & 148 & 0,4 \\
8 & 71 & 16 & 196 & 0,4 \\
\hline
\end{tabular}

LAS40 = duration of the low amplitude signal $(<40 \mu \mathrm{V})$ for the last $40 \mathrm{~ms}$ of the QRS; RMS40 = root mean square voltage for the last $40 \mathrm{~ms}$ of the complex.

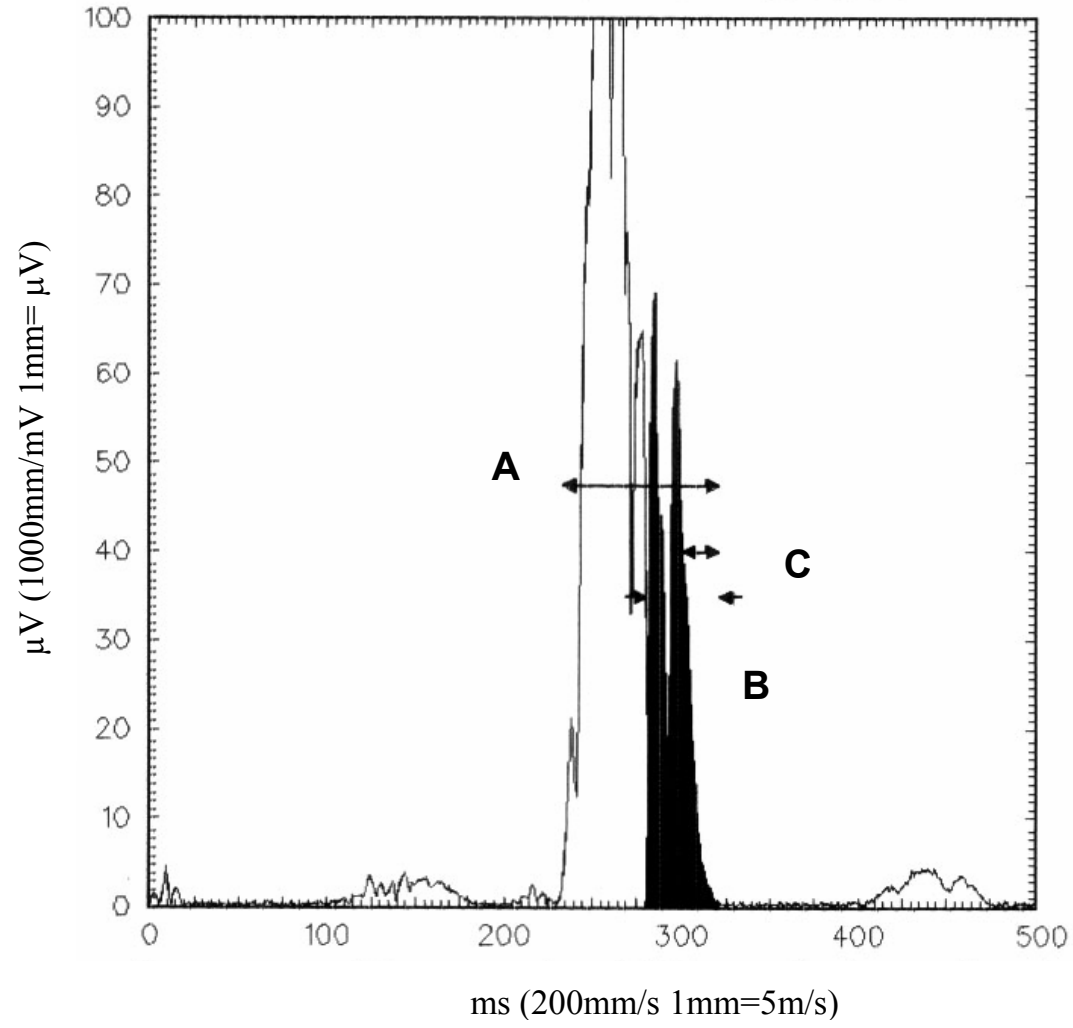

Figure 1. Characteristics of an high resolution electrocardiography (HRECG) tracing analyzed in the time domain obtained for a dog with chronic chagasic myocardiopathy. A: duration of the filtered QRS $(84 \mathrm{~ms})$; B: duration of the low amplitude signal (below $40 \mu \mathrm{V})$ for the last $40 \mathrm{~ms}$ of the QRS complex (16ms); C: root mean square voltage for the last $40 \mathrm{~ms}$ of the QRS complex $(74 \mu \mathrm{V})$. 


\section{Ferreira et al.}

Table 2. Means and standard deviation of high resolution electrocardiography variables obtained for the eight adult dogs with chronic chagasic myocardiopathy submitted to different anesthetic protocols

\begin{tabular}{|c|c|c|c|c|c|}
\hline \multirow{2}{*}{$\begin{array}{c}\text { Anesthetic } \\
\text { protocol }\end{array}$} & \multicolumn{5}{|c|}{ Variable } \\
\hline & $\begin{array}{l}\text { QRS } \\
\text { (ms) }\end{array}$ & $\begin{array}{l}\text { LAS40 } \\
\text { (ms) }\end{array}$ & $\begin{array}{c}\text { RMS40 } \\
(\mu \mathrm{V})\end{array}$ & $\begin{array}{c}\text { Noise Level } \\
(\mu \mathrm{V})\end{array}$ & Heart Rate (bpm) \\
\hline $\mathrm{T} 1$ & $71,50 \pm 8,62 \mathrm{~A}$ & $16,62 \pm 4,03 \mathrm{~A}$ & $199,75 \pm 119,82 \mathrm{~A}$ & $0,46 \pm 0,07 \mathrm{~A}$ & $91,87 \pm 20,49 B$ \\
\hline $\mathrm{T} 2$ & $72,00 \pm 7,48 \mathrm{~A}$ & $18,00 \pm 3,07 \mathrm{~A}$ & $207,37 \pm 107,10 \mathrm{~A}$ & $0,42 \pm 0,11 \mathrm{AB}$ & $95,25 \pm 19,22 B$ \\
\hline $\mathrm{T} 3$ & $72,00 \pm 8,03 \mathrm{~A}$ & $17,75 \pm 1,90 \mathrm{~A}$ & $230,25 \pm 134,16 \mathrm{~A}$ & $0,40 \pm 0,07 \mathrm{AB}$ & $89,62 \pm 12,68 \mathrm{~B}$ \\
\hline $\mathrm{T} 4$ & $72,87 \pm 6,83 \mathrm{~A}$ & $17,62 \pm 3,15 \mathrm{~A}$ & $173,25 \pm 79,28 \mathrm{~A}$ & $0,32 \pm 0,04 \mathrm{~B}$ & $86,12 \pm 12,51 \mathrm{~B}$ \\
\hline T5 & $71,75 \pm 8,10 \mathrm{~A}$ & $17,37 \pm 3,54 \mathrm{~A}$ & $196,87 \pm 107,53 \mathrm{~A}$ & $0,32 \pm 0,07 \mathrm{~B}$ & $100,37 \pm 14,28 \mathrm{~B}$ \\
\hline T6 & $71,50 \pm 7,61 \mathrm{~A}$ & $17,50 \pm 3,66 \mathrm{~A}$ & $221,37 \pm 111,55 \mathrm{~A}$ & $0,33 \pm 0,05 \mathrm{~B}$ & $132,87 \pm 19,43 \mathrm{~A}$ \\
\hline
\end{tabular}

Means followed by at least one different letter differ $(5 \%$ Tukey test, $\mathrm{P}<0.05)$. T1 = animals not submitted to tranquilization or anesthesia; T2 = tranquilization with acepromazine, T3 = tranquilization with a combination of acepromazine and buprenorphine, T4 $=$ general inhalatory anesthesia with isoflurane, T5 $=$ general inhalatory anesthesia with sevoflurane, T6 $=$ anesthesia with propofol.

\section{DISCUSSION}

Good quality tracings were obtained with the HRECG technique employed. According to Calvert (1998), factors that might compromise the electrocardiographic recordings include muscle tremors, a heart rate above $140 \mathrm{bpm}$ and slurring of the ST segment. The last two factors impair the identification of the end part of the QRS complex, whose correct identification is necessary for the establishment of the indices measured (QRS, LAS40 and RMS40). No alterations that would compromise the HRECG analysis were observed in the animals studied here.

Kushner et al. (1996) observed that tranquilization with acepromazine and buprenorphine facilitated the HRECG recording without altering the results. No significant difference in the noise level was observed between control animals and animals receiving acepromazine or acepromazine plus buprenorphine. The animals were more adapted to confinement, showing a low noise level in the HRECG recordings even in the absence of the effect of tranquilization or anesthesia. Thus, tranquilization alone was not enough to promote a more intense reduction in the noise level compared to group 1.

Another difference between the two studies refers to the evaluated animals. Tranquilization or anesthesia might be necessary to obtain an HRECG recording in dogs with different heart diseases that are at an increased risk of developing severe cardiac arrhythmias. Kushner et al. (1996) studied clinically normal dogs, whereas in the present study elderly dogs bearer of myocardiopathy with a potential to develop ventricular arrhythmias were used. The latter approach confers greater clinical applicability to the results obtained. One of the studied animals showed an altered HRECH recording compatible with the occurrence of a late potential.

Receiving acepromazine, the 10-min interval between administration of the drug and the beginning of the electrocardiographic recording was established based on previous pilot studies showing no difference in the noise level between recordings that were obtained 20 or $30 \mathrm{~min}$ after administration. It should be emphasized that in the present study each recording lasted $16 \mathrm{~min}$. No mention regarding the interval between drug administration and the beginning of the electrocardiographic recording is made in the tranquilization protocol used by Kushner et al. (1996).

A study involving humans conduced by Steinberg and Bigger (1989) compared the sensitivity of HRECG in detecting late potentials at different noise levels. Late potentials were identified in a significantly larger percentage of patients when the mean noise level was $0.58 \mu \mathrm{V}$. Similarly, the American Heart Association recommends a noise level of less than $0.7 \mu \mathrm{V}$ (Dunbar and Denes, 1993).

With respect to the effects of propofol, the obtained data agree with those reported by Massone (1999) who observed a reduction in blood arterial pressure with the use of this anesthetic. The increase in heart rate observed 
here might be compensatory in order to preserve cardiac output.

The rapid anesthetic induction provided by propofol facilitated orotracheal intubation of the animals submitted to general inhalatory anesthesia (treatments 4 and 5). The 30-min interval between the beginning of inhalatory anesthesia and the HRECG recording was defined to ensure the elimination of the effects of propofol. According to Thurmon et al. (1999), at the clinical dose used anesthetic recovery is complete within $20 \mathrm{~min}$. Thus, the exclusive aim of this agent in treatments 4 and 5 was to permit orotracheal intubation.

Likewise, in the group that received only propofol (treatment 6), the choice for continuous infusion was based on reports of the short duration of the effect of the drug (Quandt et al., 1998). The HRECG recordings lasted 16min. The use of a single dose of propofol may not have provided an anesthetic effect lasting throughout the electrocardiographic recording.

Although no significant alteration in heart rate was observed with the use of acepromazine, the drug may cause reflex tachycardia due to the hypotensive effects of phenothiazine derivatives. In patients with heart disease, this action may further aggravate the decrease in cardiac output and increase the oxygen demand of the myocardium. The combination of acepromazine and buprenorphine may be better tolerated hemodynamically. Opioids can cause brachycardia associated with an increase in vagal activity (Hell et al., 1980).

Regarding the use of volatile anesthetics, the present results agree with those reported by Morgan and Mikhail (1996) who observed that isoflurane causes minimal cardiovascular effects. Similarly, Ebert et al. (1995) reported that sevoflurane seems to be a volatile anesthetic that offers more cardiovascular stability.

In veterinary medicine, the relationship between late potentials and chronic chagasic myocardiopathy in dogs has not been previously investigated. The present results show that alterations in HRECG indices are not common in dogs in the undetermined chronic phase of chagasic myocardiopathy.
The drugs used had no effect on the HRECG of the animal that presented a late potential. No studies regarding the action of tranquilizing or anesthetic agents in patients with altered HRECG are available in the literature. Thus, the data obtained here are reported for the first time and may represent further indicators in the evaluation of preanesthetic and anesthetic drugs.

\section{CONCLUSION}

Anesthesia with isoflurane, sevoflurane and propofol facilitated the HRECG recording by providing an adequate reduction in the noise level without altering the electrocardiographic indices obtained.

\section{REFERENCES}

CALVERT, C.A. Hight resolution electrocardiography. Vet. Clin. N. Am.: Small Anim. Pract., v.6, p.1429-1447, 1998.

DUNBAR, D.N.; DENES, P. Operational aspects of signal-averaged electrocardiography. Prog. Cardiov. Dis., v.35, p.329-348, 1993.

EBERT, T.J.; HARKIN, C.P.; MUZI, M. Cardiovascular responses to sevoflurane; a review. Anesth. Analg., v.81, p.11-22, 1995.

HATÉM, D.M.; GUS, M.; HALPERIN, C. Aplicações clínicas da eletrocardiografia de alta resolução. Arq. Bras. Cardiol., v.60, p.357-360, 1993.

HELL, R.C.; BROGDEN, R.N.; SPEIGHT, T.M. et al. Buprenorphine: a review of its pharmacological properties and therapeutic efficacy. Drugs, v.17, p.81-110, 1980.

JACOBS, G.J. Cardiomyopathies: their classification and pathophysiologic features. Vet. Med., v.91, p.436-444, 1996.

JANSE, M.J.; OPTHOF, T.; KLEBER, A.G. Animal models of cardiac arrhythmias. Cardiovasc. Res., v.39, p.165-177, 1998.

KLEIN, R.P.; CAMACHO, A.A. Electrocardiographic evaluation of dogs experimentally infected with Trypanossoma cruzy during the acute and indeterminate chronic phases of infection. Braz. J. Vet. Res. Anim. Sci., v.34, p.337-334, 1997. 


\section{Ferreira et al.}

KUSHNER, L.I.; CALVERT, C.A.; BOYLE, C. R. Effects of acepromazine and buprenorphine on measured of the signal-averaged electrocardiogram in healthy dogs. Am. J. Vet. Res., v.57, p.1511$1514,1996$.

MASSONE, F. Anestesiologia veterinária: Farmacologia e técnicas. 3.ed. Rio de Janeiro: Guanabara Koogan, 1999. p.252-253.

MOFFA, P.J. Eletrocardiografia de alta resolução. In: FRIEDMANN, A.A.; GRINDLER, J. Eletrocardiografia básica. São Paulo: Sarvier, 2000. p.123-128.

MORGAN, G.E.; MIKHAIL, M.S. Inhalational anesthetics. In: Clinical anesthesiology. 2.ed. Stamford: Appleton \& Lange, 1996. p.109-127.
QUANDT, J.E.; ROBINSON, E.P.; RIVERS, W.J. et al. Cardiorespiratory and anesthetic of propofol and thiopental in dogs. Am. J. Vet. Res., v.59, p.1137-43, 1998.

STEIMBERG, J.S.; BIGGER, J.T. Importance of the endpoint of noise reduction in analysis of the signal-averaged electrocardiogram. Am. J. Cardiol., v.63, p.556-560, 1989.

THURMON, J.C.; TRANQUILLI, W.J.; BENSON, G.J. Essencials of small animal anesthesia \& analgesia. 1.ed. Philadelphia: Lippincott Willians \& Wilkins, 1999. 580 p.

ZAR, J.H. Biostatistical analysis. New Jersey: Prentice Hall, 1996. 224p. 